\title{
An unusual mucous cyst of the lung
}

\author{
F J SAMBROOK GOWAR
}

From the Department of Thoracic Surgery, Aberdeen Royal Infirmary, Aberdeen AB9 2ZB, UK

Sambrook Gowar, F J (1978). Thorax, 33, 796-799. An unusual mucous cyst of the lung. A 68-year-old woman presented with a multilocular mucous cyst of the lung. At operation numerous seedling cysts were present on the parietal pleura, and the appearances strongly resembled those found in pseudomucinous cystadenoma of the ovary. The histological features suggested that the lesion was an unusual benign mucous cyst of the bronchus. After lobectomy and removal of pleural masses the patient has remained free from recurrence for five years.

\section{Case report}

An unmarried woman of 68 years suddenly developed acute pain under her right lower ribs in June 1972. The pain eased after an hour or two but became worse when she went to bed. She was unable to lie on the right side and walked about all night to get relief. The pain persisted on and off for eight days, but there was no nausea or vomiting.

A chest radiograph showed a large ovoid mass inseparable from the mediastinum, lying posteriorly in the right lower zone (figs 1 and 2). The patient was transferred to the Aberdeen Thoracic Surgery

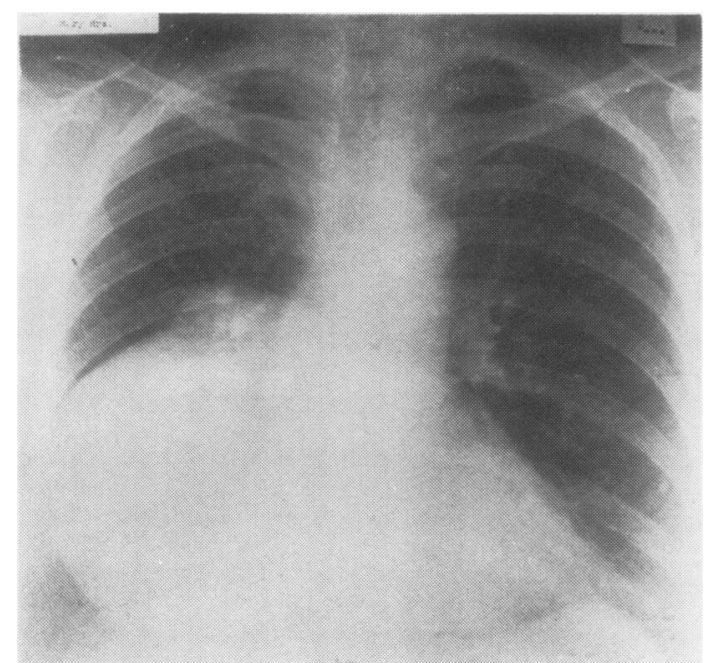

Fig 1 Chest radiograph $(P A)$ showing large cyst in right lower lobe.
Unit with a provisional diagnosis of pulmonary hydatid cyst.

She was obese, weighing $84 \mathrm{~kg}$. Dullness and diminished breath sounds were noted at the base of the right lung where a few rales were heard. The heart rate was $100 / \mathrm{min}$ and regular, and no murmurs were heard. Blood pressure was $150 / 90 \mathrm{mmHg}$. There was slight pitting oedema of the ankles. Results of abdominal and gynaecological examinations were negative.

At bronchoscopy granulations were seen in the right apical lower segmental bronchus. After these had been removed for biopsy, a bluish cystic lesion

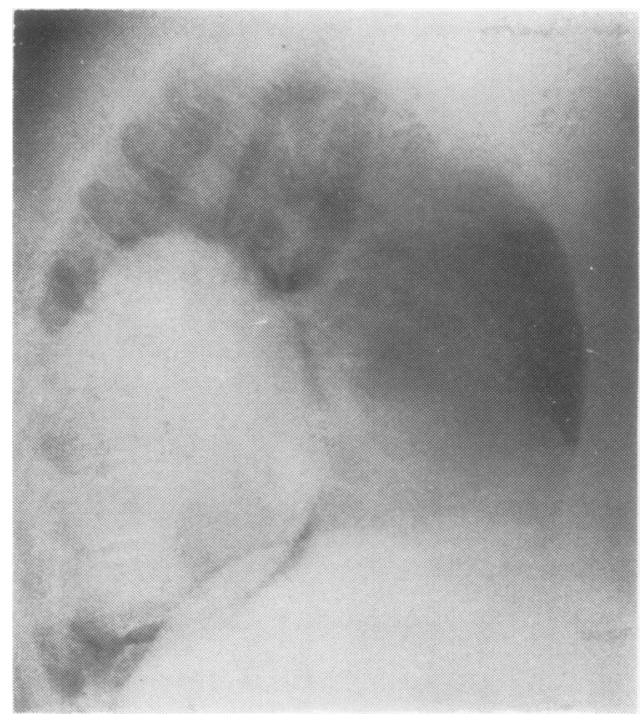

Fig 2 Chest radiograph (right lateral) showing position of cyst. 


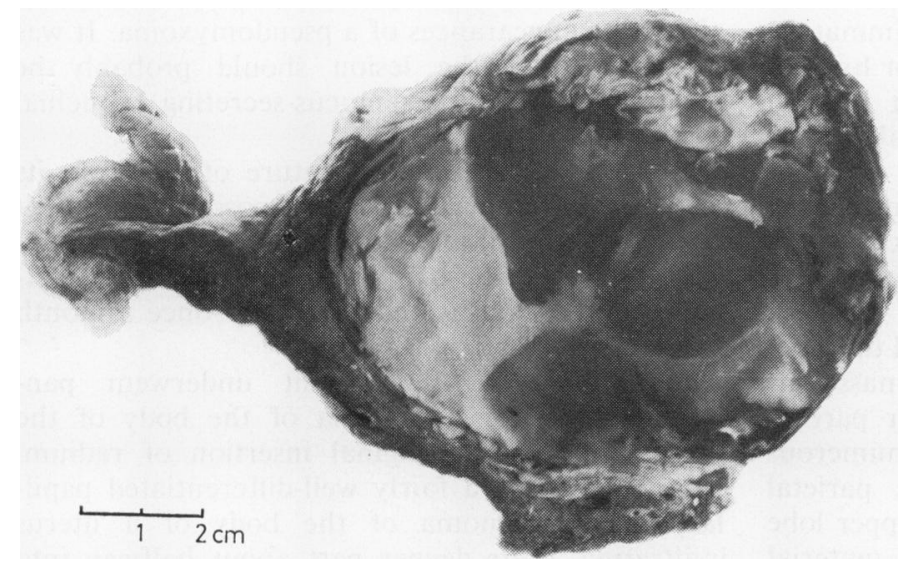

Fig 3 Right lower lobe sectioned to show multilocular mucous cyst.

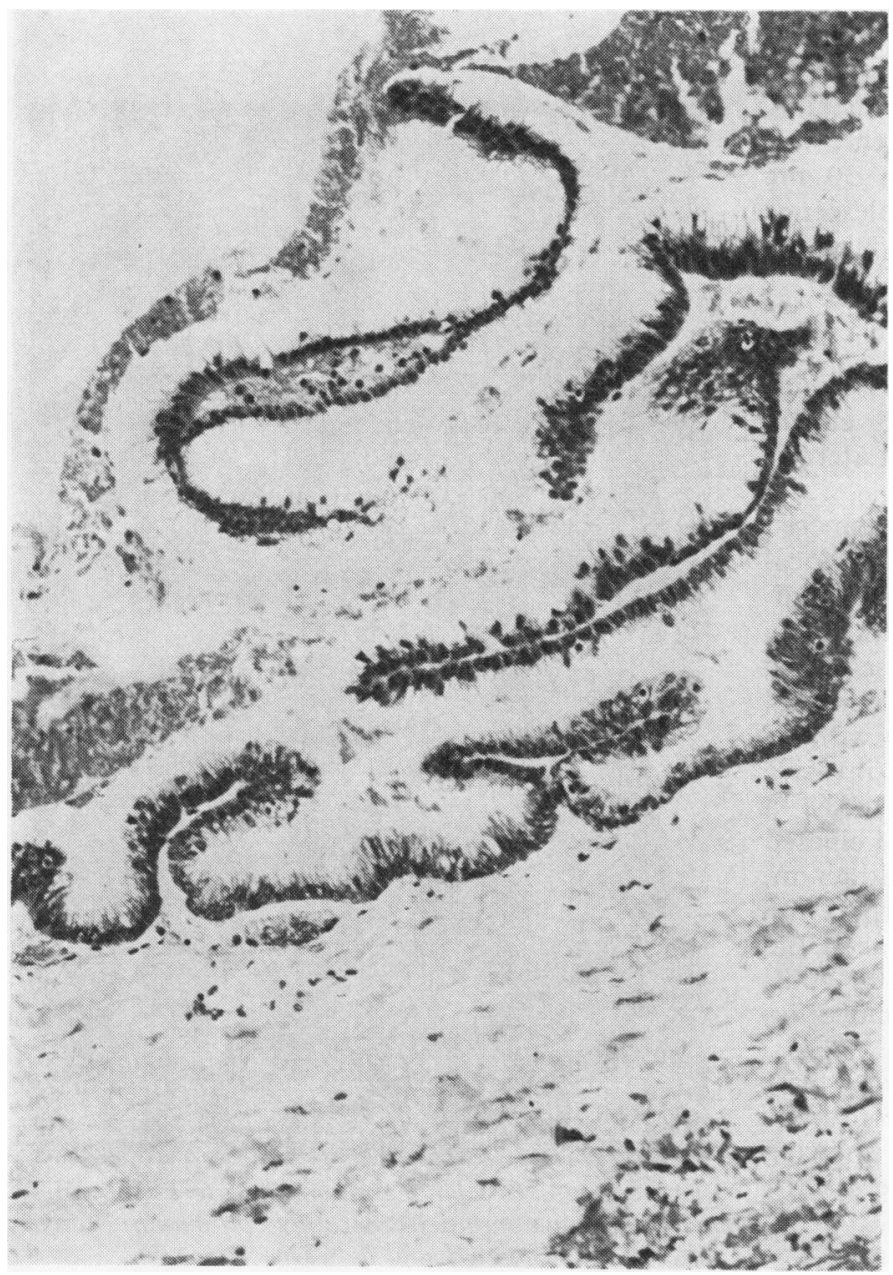

Fig 4 Lining of cyst composed of complex folds of mucus-secreting epithelium of uniform appearance (Haematoxylin and Eosin $\times 132$ ). 
resembling the lining of a hydatid cyst was seen in the lumen. The biopsy showed inflammatory changes but no evidence of malignancy or hydatid disease. Casoni and hydatid complement fixation tests gave negative results as did all other investigations.

The diagnosis appeared to rest between hydatid cyst of the lung and mediastinal neurofibroma, and it was thought that the bronchoscopic findings favoured the former.

On 4 August 1972 a right posterolateral thoracotomy was performed. A large cystic mass was found lying superficially in the posterior part of the right lower lobe, and there were numerous smaller cystic masses attached to the parietal pleura. While being dissected from the upper lobe the cyst ruptured, and much gelatinous material was extruded, the appearance being reminiscent of pseudomucinous ovarian cyst. Frozen section of the cyst wall showed no evidence of hydatid disease or carcinoma. Lower lobectomy was performed, and several cystic masses were removed from the diaphragmatic and costal pleura, but inevitably clearance was incomplete. The phrenic nerve was crushed above the diaphragm. Thiotepa $30 \mathrm{mg}$ was injected into the pleural cavity. Convalescence was uneventful, and she was discharged on 23 August 1972.

\section{PATHOLOGY}

The right lower lobe of the lung contained a peripheral thin-walled multilocular cyst $15 \mathrm{~cm}$ in diameter, filled with thick grey mucus. Laterally the wall was thickened to $5 \mathrm{~cm}$ (fig 3).

Histologically, the thickened area was composed of dense hyalinised fibrous tissue showing focal chronic inflammation and surrounded by compressed lung tissue. The cyst was discontinuously lined by papilliform columnar mucus-secreting epithelium, which in places had a lower cuboidal appearance (fig 4). The cells were regular with no mitoses, and there was no suggestion of invasive growth. At one point there appeared to be a transition to tall columnar pseudostratified ciliated epithelium similar to normal bronchial epithelium. The cyst contained mucoid material incorporating much cellular debris, and in many places the mucus permeated the cyst wall and lay in pools in the fibrous tissue. Very occasional calcification was noted.

Two separate specimens from pleura were fatty and fibrous tissue masses containing mucoid cysts respectively 7 and $5 \mathrm{~cm}$ in diameter showing histological features identical with those of the pulmonary cyst.

The permeation of fibrous tissue by mucin was regarded as a passive process after local rupture giving the appearances of a pseudomyxoma. It was concluded that the lesion should probably be regarded as a complex mucus-secreting bronchial cyst.

In view of the unusual nature of the cyst, its incomplete removal, and the possibility that it might be a low-grade adenocarcinoma, the patient was given a course of thiotepa $15 \mathrm{mg}$ once a fortnight for 12 months and thereafter once a month for another year.

In July 1974 the patient underwent panhysterectomy for carcinoma of the body of the uterus followed by vaginal insertion of radium. The lesion was "a fairly well-differentiated papillary adenocarcinoma of the body of a uterus infiltrating at its deeper part about halfway into the myomentrium. There is mild chronic cervicitis. The tubes are normal and the ovaries atrophic" (fig 5). Histological comparison of the

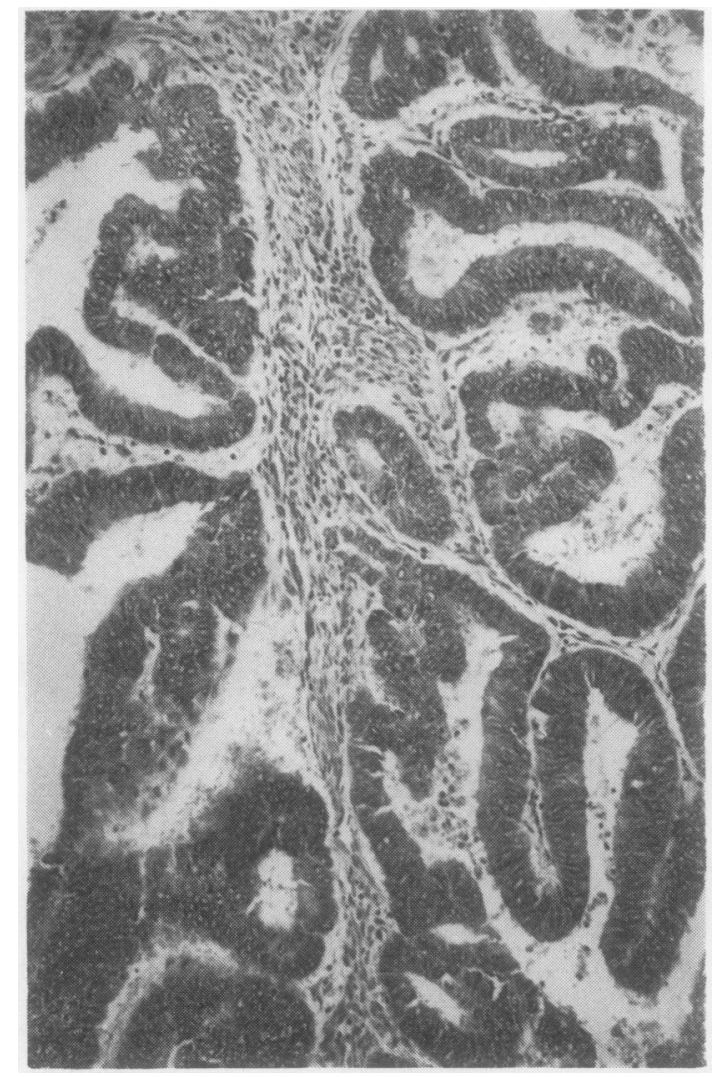

Fig 5 Section of adenocarcinoma of uterus showing tall columnar non-mucus secreting epithelium. Many mitoses are visible ( $H$ and $E \times 126)$. 
uterine carcinoma with the pulmonary cyst failed to show any relation between the two lesions.

In May 1976 a small vaginal recurrence of growth was treated by excision and radium implant.

The patient remains well (December 1977). Her chest is clear clinically and radiologically, and there has been no further recurrence of the uterine carcinoma.

The untimely death in 1974 of Dr A C de C Kerr who referred the case to the Aberdeen
Thoracic Unit and who was to have shared in this report is deeply regretted. I am indebted to Dr G B Scott (Aberdeen) and Dr Henry Richmond (Inverness) for the pathology reports and to Professor A L Stalker (Aberdeen) for reviewing the histology.

Requests for reprints to: Mr F J Sambrook Gowar, Department of Thoracic Surgery, Aberdeen Royal Infirmary, Aberdeen AB9 2ZB. 